April 2008

\title{
Surgical management of metastatic disease to the adrenal gland
}

Paul R. Gittens Jr.

Thomas Jefferson University

Allison F. Solish

Thomas Jefferson University

Edouard Trabulsi

Thomas Jefferson University

Follow this and additional works at: https://jdc.jefferson.edu/urologyfp

Part of the Urology Commons

Let us know how access to this document benefits you

\section{Recommended Citation}

Gittens, Paul R. Jr.; Solish, Allison F.; and Trabulsi, Edouard, "Surgical management of metastatic disease to the adrenal gland" (2008). Department of Urology Faculty Papers. Paper 1.

https://jdc.jefferson.edu/urologyfp/1

This Article is brought to you for free and open access by the Jefferson Digital Commons. The Jefferson Digital Commons is a service of Thomas Jefferson University's Center for Teaching and Learning (CTL). The Commons is a showcase for Jefferson books and journals, peer-reviewed scholarly publications, unique historical collections from the University archives, and teaching tools. The Jefferson Digital Commons allows researchers and interested readers anywhere in the world to learn about and keep up to date with Jefferson scholarship. This article has been accepted for inclusion in Department of Urology Faculty Papers by an authorized administrator of the Jefferson Digital Commons. For more information, please contact: JeffersonDigitalCommons@jefferson.edu. 


\section{Surgical Management of Metastatic Disease to the Adrenal Gland}

Paul R. Gittens Jr, Allison F. Solish, and Edouard J. Trabulsi

Department of Urology

Thomas Jefferson University

Philadelphia, PA.

Address correspondence to

Edouard J. Trabulsi, MD

Department of Urology

Thomas Jefferson University

1015 Walnut St, Suite 1102

Philadelphia, PA 19107

E-mail: Edouard.trabulsi@jefferson.edu

\section{Abstract}

Metastatic disease to the adrenal glands can occur in a wide array of malignancies. With the increased use of abdominal imaging, these lesions are diagnosed with more frequency. Diagnostic and laboratory evaluation is essential for the differentiation of benign lesions from primary malignant adrenal tumors or extra-adrenal metastasis. Computed tomography (CT) and magnetic resonance imaging (MRI) characteristics, as well as the adjunctive use of immunocytochemical techniques on biopsy specimens, can allow accurate identification of metastatic lesions. Surgical management of metastastic lesions is appropriate in selected patients, primarily when representing the solitary site of metastatic disease. The surgical approach, while debatable, can de done either through open surgery or laparoscopically. Either approach appears comparable in terms of oncologic efficacy in the carefully selected patient, although laparoscopic adrenalectomy is associated with decreased pain 
and improved convalescence. The surgeon's skill in laparoscopic technique, appropriate patient selection, and the ability to adhere to oncologic principles, including complete excision without tumor spillage, are of utmost importance when deciding the appropriate surgical intervention.

The adrenal gland is a common site of metastasis and can be afflicted by malignancies from a multitude of primary sites. ${ }^{1-3}$ The rich sinusoidal blood flow and multiple pathways of arterial blood supply may contribute to the high incidence of metastatic implantation. ${ }^{1,3}$ In one autopsy review of 1,000 patients with malignancy, metastases to the adrenal glands were found in $27 \%$ of patients. ${ }^{2}$ The most common sites metastasizing to the adrenal glands are breast, lung, gastrointestinal tract, skin (melanomas), and kidney. Lung and breast cancers have been found to account for approximately $39 \%$ and $35 \%$ of adrenal metastases, respectively, and adrenal metastases can be seen in up to $40 \%$ to $50 \%$ of patients with melanomas and liver or renal cell cancers. ${ }^{2-4}$

Patients with adrenal metastasis are typically asymptomatic but can uncommonly present with back pain, retroperitoneal hemorrhage, or adrenal insufficiency. ${ }^{1,5}$ In one study, symptomatic metastases were larger in size when compared to asymptomatic lesions and also were 
associated with a significantly younger patient population. ${ }^{5}$

Overwhelmingly, however, the majority of adrenal metastases are either discovered incidentally during the staging workup for a primary malignancy or identified on repeat radiological studies for surveillance after initial treatment. Over a 30-year period, Lam and Lo found that adrenal metastases were most frequently discovered within a relatively brief period of time after detection of the primary malignancy (median latent period, 7 months), with less than $2 \%$ of cases having metastases to the adrenals more than 5 years after diagnosis. ${ }^{5}$

\section{Imaging}

Improvements in imaging techniques have allowed the ready detection and characterization of adrenal gland metastases. ${ }^{6-12}$ Computed tomography (CT) with and without oral and intravenous iodinated contrast is useful in assessing adrenal lesions. Oral contrast should be given to distinguish the adrenal glands from surrounding organs. On CT, metastatic lesions are generally nonspecific and can have a wide array of radiographic features. The size can vary from less than a centimeter to a large mass. They may have a discrete focus or be multifocal; they can be smooth, irregular, or have a lobulated contour. Lesions can be unilateral or bilateral, can show evidence of local invasion, and may be associated with hemorrhage. Calcifications are a rare finding in metastatic lesions, but necrosis may be present. Intracellular lipid content and vascular 
enhancement are two CT criteria that can be useful in differentiating benign adenomas from malignant adrenal masses. ${ }^{6}$ Metastatic lesions typically have low levels of intracytoplasmic fat in the adrenal cortex as compared to adenomas ( $70 \%$ of cases) and will have lower attenuation than adenomas on noncontrast $\mathrm{CT} \cdot{ }^{6,7,10,11}$ After the administration of iodinated contrast there is usually a more obvious heterogeneous enhancement pattern compared to adenomas and a significantly delayed contrast material washout. ${ }^{6,7,9}$

Magnetic resonance imaging (MRI) is another useful tool for evaluating metastatic lesions to the adrenal glands. MRI can be used in patients who have a contraindication to intravenous contrast, particularly those with an iodine allergy or those in renal insufficiency. T1-weighted magnetic resonance images of metastatic tumors have a signal intensity that is similar to adrenal adenomas and may be confused with benign lesions. ${ }^{6,7}$ On T2-weighted imaging, lesions are likely to be heterogeneous and hyper-intense when compared to liver. T2-weighted imaging with opposed-phase imaging (in and out of phase) will show no decrease in intensity secondary to the decreased lipid content in the mass. After the administration of intravenous gadoliniumcomplex, most tumors are hyper-intense and show heterogeneous enhancement. Using T2-weighted fat-suppressed images, MRI may distinguish between normal and neoplastic tissue. ${ }^{7}$ 
Ultrasonography may detect adrenal lesions that are larger than 2 $\mathrm{cm}$. However, ultrasound has not been as useful as CT in the evaluation of metastatic adrenal lesions. ${ }^{13,14}$ The sensitivity and specificity for ultrasound were found to be $79 \%$ and $61 \%$, respectively, as compared to $84 \%$ and $98 \%$ for $\mathrm{CT} .{ }^{13}$ Operator experience, body habitus, bowel gas, and lack of specific imaging patterns are all impeding factors. Preliminary results with positron emission tomography (PET) have shown some promise in differentiating malignant lesions using 18-fluorodeoxyglucose, but further studies are needed to better define the role of this technology in assessing adrenal lesions. ${ }^{6}$

\section{Clinical and Serological Diagnosis}

Establishing a diagnosis of metastatic disease versus benign disease is paramount. As discussed, metastatic lesions can have nonspecific findings on imaging and thus can overlap with benign adrenal masses in size and radiological detail. Patients should be questioned for signs and symptoms of a metabolically active primary adrenal tumor, such as hypertension, tachycardia, headache, palpitations, hirsutism, or change in body habitus. A physical examination should be performed looking for the stigmata of the other etiologies of adrenal pathology, including examination for lymphadenopathy, thyroid lesions, and genitourinary abnormalities. Serum electrolytes, as well as urine and serum analysis for aldosterone, cortisol, sex hormone steroids, and catecholamines and 
their metabolites such as metanephric acid, should be performed to evaluate for primary adrenal tumors. ${ }^{15,16}$

\section{Biopsy}

Fine-needle aspiration (FNA) with CT guidance can be performed safely and is highly sensitive and specific for diagnosing adrenal metastasis. ${ }^{17,18}$ FNA also is useful for defining a primary malignancy of unknown origin. The accuracy of FNA has improved with advances in immunocytochemistry techniques, which have a specificity and sensitivity reported to be as high as $85 \%$ to $94 \%$ and $100 \%$, respectively. ${ }^{17}$ The best diagnostic results are obtained when a cytopathologist and cytotechnology assistant are present while specimens are obtained at the time of FNA. Some cytologic indicators of metastatic lesions are increased nuclear hyperchomasia, prominent nucleoli, necrotic debris, and intact cells with increased nuclear/cytoplasmic ratios. The complication rate of FNA have been reported to be approximately $3.0 \%$, which may include hemorrhage, infection, theoretical risk of tumor tract seeding, and capsular disruption. ${ }^{17,19}$ There is also the risk of biopsy of an unrecognized pheochromocytoma, which can cause life-threatening hemodynamic instability. In a review by Fassancht et al, in patients with a nonmetabolically active adrenal mass and inconclusive imaging, the authors recommended an adrenal biopsy in the absence of other metastasis. ${ }^{16}$ 


\section{Surgical Management of Adrenal Metastasis}

Surgical management of an adrenal lesion is indicated for the removal of functional and nonfunctional tumors, including pheochromocytoma, solid adrenal masses not meeting radiographic criteria as benign lesions, and lesions greater than $5 \mathrm{~cm} .{ }^{20}$ Open surgical adrenalectomy can be performed by a variety of means, including posterior and modified posterior, flank, and transabdominal approaches. Laparoscopic adrenalectomy has emerged as the treatment of choice for benign functioning and nonfunctioning adrenal disorders requiring surgery. Most commonly, a transperitoneal approach is performed, but retroperitoneal laparoscopy can be used. ${ }^{20}$ The choice of technique and approach depends largely on the surgeon's experience and preference, size and location of the tumor, body habitus, previous intra-abdominal surgery, or previous adhesions. Contraindictions to laparoscopy include pregnancy, large tumors $\left(\_8 \mathrm{~cm}\right)$, or if primary invasive adrenocortical carcinoma is suspected on imaging. ${ }^{20,21}$ Other relative contraindications include morbid obesity, prior intraabdominal surgery, and large pheochromocytomas.

Several series confirm that surgical management of a metastatic adrenal lesion does improve survival in select patients and can lead to potential cure. ${ }^{19,22-32}$ In a series reported by Higashiyama et al, lung 
cancer patients with isolated metastatic disease to the adrenal gland who underwent surgical resection followed by adjuvant chemotherapy or radiotherapy fared much better than patients treated non-operatively. ${ }^{27}$ This study demonstrated a median survival of less than 6 months for patients treated medically, and survival benefit of greater than 9 months in the surgical group, with one patient showing no disease progression after 40 months. Luketich and Burt found a 3-year actuarial survival of $38 \%$ in solitary adrenal metastatic lesions from non-small cell lung cancer managed with chemotherapy followed by adrenalectomy compared with chemotherapy alone. ${ }^{26}$ The survival in the surgery group was significantly improved with a median of 31 months, versus 8.5 months, and all of the patients in the chemotherapy group without surgery died within 22 months. ${ }^{26}$

Several studies have tried to identify patients who may benefit from surgical excision of metastatic adrenal lesions. Adrenalectomy has been found to be most beneficial when the primary cancer is controllable and when there is no evidence of extra-adrenal metastases. ${ }^{30}$ Siemer et al examined renal cell cancer patients and noted that patients with a solitary adrenal metastasis achieved a significant tumor-specific survival benefit with a median survival of 68 months compared to a median survival of 10 months in those patients with additional metastatic foci. ${ }^{25}$ Risk factors such as the site of the primary cancer, size, histology, primary tumor type (adenocarcinoma possibly being more favorable), presence of other 
distant metastases, local invasion, and a lengthy disease-free interval after initial diagnosis appear to impact on cancer survival, but these risk factors have been somewhat variable..$^{4,25-33}$

The optimal surgical approach for adrenalectomy for metastatic lesions, either laparoscopic or open surgery, is somewhat controversial. The majority of data regarding improved survival after adrenalectomy have focused primarily on open surgical techniques. In a series from Memorial Sloan-Kettering Cancer Center, Kim et al examined 37 patients who underwent open adrenalectomy, and found a 5 -year survival of $24 \%$ (median survival, 21 months). ${ }^{29}$ They found that complete resection and a disease-free interval of greater than 6 months were predictors of survival. Advocates of open adrenalectomy voice many concerns with laparoscopy, such as the possibility of tumor seeding and subsequent carcinomatosis due to carbon dioxide insufflation, violation of the adrenal gland and tumor spillage, the possible immunosuppressive affects of the pneumoperitoneum, and potential port site metastasis as reasons to avoid laparoscopic surgery. ${ }^{28,30,34,35}$ Additionally, Kebebew et al demonstrated that inadvertent laparoscopic resection of clinically unsuspected adrenocortical carcinoma exhibited a high local recurrence rate. ${ }^{19}$ Gerber et al reported on their experience with laparoscopic adrenalectomy for lung cancer patients with a solitary metastasis to the adrenal gland. ${ }^{36}$ They found that these patients had an inflammatory reaction that made dissection during laparascopy more difficult than with benign disease to 
the adrenal gland, and concluded that lesions greater than $5 \mathrm{~cm}$ are less amenable to laparoscopic adrenalectomy and have a higher rate of open conversion.

The incidence of port site metastasis has been estimated to be from $0 \%$ to $6.25 \% .{ }^{35}$ Causes of port site metastasis can be grouped into several categories: tumor aggressiveness (type of tumor and its natural behavior), local wound factors (implanting in the early stages of wound healing, tumor cell adherence to wound margins, and release of growth factors), host immune response, and laparoscopy-related factors (ie, type of gas used for insufflation, surgical manipulation, tumor spillage). ${ }^{35}$ In their review of the urologic literature, Tsvian et al found nine cases of port site metastasis. The putative causative factors of port site metastasis were high stage or grade primary tumor, violation of tumor boundaries, intracorporeal morcellation of the tumor specimen, and disuse of an entrapment bag during specimen retrieval. Other potential risk factors were pre-existing immunosuppression and the presence of ascites. ${ }^{35,37}$

There have been contradictory reports on the role of the pneumoperitoneum as the cause of port site metastasis and carcinomatosis. ${ }^{38-40}$ In an novel study by Ikramuddin et al, carbon dioxide effluent recovered from patients with cancer during laparoscopy was examined. ${ }^{40}$ The authors concluded that malignant cells are aerosolized 
in laparoscopic surgery, but in patients without carcinomatosis, aerosolization is unlikely to contribute to port site metastasis.

Many proponents of laparoscopic surgery suggest that laparoscopic adrenalectomy is oncologically comparable to open surgery for the management of metastatic lesions to the adrenal in the selected patient. In regards to port site seeding, proponents state that open adrenalectomy is not exempt from wound recurrences. There is an approximately $0.4 \%$ chance of metastasis in surgical scars after open surgery for renal cell carcinoma. ${ }^{41}$ Laparoscopic adrenalectomy may have several advantages over open surgical approaches. When compared to open surgery, laparoscopy has demonstrated superior operative times, analgesic requirements, postoperative complications, hospital stay, and mean operative blood loss. ${ }^{42,43}$ Laparoscopic adrenalectomy appears to confer the same survival benefit as open surgery. ${ }^{31,44}$ Sarela et al found no difference in the median survival between open adrenalectomy and laparoscopic adrenalectomy. ${ }^{45}$ In another series, 31 patients underwent laparoscopic adrenalectomy for metastatic lesions from several primary tumors, primarily colon, lung, and renal cell cancers. ${ }^{30}$ The 5 -year actuarial survival rate was $40 \%$ with a median follow-up of 26 months, which was favorable when compared to historical open adrenalectomy series. The authors emphasized that proper patient selection was critical, and small organ-confined adrenal masses were best suited for a laparoscopic procedure. Specific contraindications to laparoscopic 
adrenalectomy were irregular adrenal masses with peri-adrenal infiltration into adjacent organs. The authors suggested that a laparoscopic approach should be abandoned if there are concerns regarding the adequacy of wide excision, and care should be taken not to violate the adrenal mass, to avoid tumor spillage, and to remove the specimen intact rather than through morcellation, with the use of a laparoscopic bag to withdraw the specimen.

Alternative approaches to the treatment of metastatic disease to the adrenal gland have been examined. ${ }^{43,44,46,47}$ Percutaneous radiofrequency ablation (RFA) has exhibited some promise in treating malignant adrenal tumors. ${ }^{43,44}$ RFA utilizes alternating radiofrequencies, which generate heat and lead to tissue necrosis and destruction. In a preliminary study of RFA of metastatic adrenal lesions, tumor recurrence occurred in two of 11 patients after RFA treatment. ${ }^{43}$ Percutaneous ethanol ablation is another non-invasive approach that has been investigated for adrenal tumors. Ethanol is cytotoxic and thrombogenic and has shown promise in shortterm studies. ${ }^{46,47}$ Although the specific roles for RFA and ethanol ablation have not been established and long-term data are still pending, these percutaneous techniques may have promise for patients who are nonoperative candidates or those who refuse surgical intervention.

\section{Conclusion}


The surgical management of adrenal metastatic lesions has shown benefit in the survival of select patients with a variety of primary tumors. Adrenal metastesectomy also has exhibited success when used as an adjunct to chemotherapy, and has been found to be more successful than chemotherapy and radiation alone. Controversy remains over the use of laparoscopic adrenalectomy, although in a number of studies there seems to be at least a parallel survival benefit when compared to open adrenalectomy, with improved convalescence. The importance of patient selection, surgeon comfort level and experience, adequate surgical planning, and adherence to oncologic principles cannot be overstated when performing laparoscopic adrenalectomy for metastastic lesions.

\section{References}

1. Kung AW, Pun KK, Lam K, Wang C, Leung CY. Addisonian crisis as presenting feature in malignancies. Cancer. 1990;65:177-9.

2. Abrams HL, Spiro R, Goldstein N. Metastases in carcinoma; analysis of 1000 autopsied cases. Cancer. 1950;3: 74-85.

3. Bullock WK, Hirst AE Jr. Metastatic carcinoma of the adrenal. Am J Med Sci. 1953;226:521-4.

4. Mansmann G, Lau J, Balk E, Rothberg M, Miyachi Y, Bornstein SR. The clinically inapparent adrenal mass: update in diagnosis and management. Endocr Rev. 2004; 25:309-40. 
5. Lam KY, Lo CY. Metastatic tumours of the adrenal glands: a 30-year experience in a teaching hospital. Clin Endocrinol (Oxf). 2002;56:95101.

6. Mayo-Smith WW, Boland GW, Noto RB, Lee MJ. State-of-the-art adrenal imaging. Radiographics. 2001;21:995-1012.

7. Goldman SM, Coelho RD, Freire Filho Ede O, Abdala N, Szejnfeld D, Fraria J, et al. Imaging procedures in adrenal pathology. Arq Bras Endocrinol Metabol. 2004;48:592-611.

8. Belldegrun A, Hussain S, Seltzer SE, Loughlin KR, Gittes RF, Richie JP. Incidentally discovered mass of the adrenal gland. Surg Gynecol Obstet. $1986 ; 163: 203-8$.

9. Berland LL, Koslin DB, Kenney PJ, Stanley RJ, Lee JY. Differentiation between small benign and malignant adrenal masses with dynamic incremented CT. AJR Am J Roentgenol. 1988;151:95-101.

10. Kenney PJ, Stanley RJ. Calcified adrenal masses. Urol Radiol. $1987 ; 9: 9-15$.

11. Lee MJ, Hahn PF, Papanicolaou N, Egglin TK, Saini S, Mueller PR, et al. Benign and malignant adrenal masses: CT distinction with attenuation coefficients, size, and observer analysis. Radiology. $1991 ; 179: 415-8$.

12. Korobkin M, Brodeur FJ, Francis IR, Quint LE, Dunnick NR, Goodsitt M. Delayed enhanced CT for differentiation of benign from malignant adrenal masses. Radiology. 1996;200:737-42. 
13. Abrams HL, Siegelman SS, Adams DF, Sanders R, Finberg HJ, Hessel SJ, et al. Computed tomography versus ultrasound of the adrenal gland: a prospective study. Radiology. 1982;143:121-8.

14. Yeh HC. Sonography of the adrenal glands: normal glands and small masses. AJR Am J Roentgenol. 1980; 135:1167-77.

15. Ross NS, Aron DC. Hormonal evaluation of the patient with an incidentally discovered adrenal mass. N Engl J Med. 1990;323:14015.

16. Fassnacht M, Kenn W, Allolio B. Adrenal tumors: how to establish malignancy? J Endocrinol Invest. 2004;27: 387-99.

17. Kindelberger DW, Cibas ES. Evaluating metastatic carcinoma to the adrenal: utility of fine needle aspiration cytology. Pathol Case Rev. $2005 ; 10: 257-62$.

18. Welch TJ, Sheedy PF 2nd, Stephens DH, Johnson CM, Swensen SJ. Percutaneous adrenal biopsy: review of a 10-year experience. Radiology. 1994;193:341-4.

19. Kebebew E, Siperstein AE, Clark OH, Duh QY. Results of laparoscopic adrenalectomy for suspected and unsuspected malignant adrenal neoplasms. Arch Surg. 2002; 137:948-51.

20. Micali S, Peluso G, De Stefani S, Celia A, Sighinolfi MC, Grande M, et al. Laparoscopic adrenal surgery: new frontiers. J Endourol. $2005 ; 19: 272-8$. 
21. Godellas CV, Prinz RA. Surgical approach to adrenal neoplasms: laparoscopic versus open adrenalectomy. Surg Oncol Clin N Am. $1998 ; 7: 807-17$.

22. Lenert JT, Barnett CC, Jr, Kudelka AP, Sellin RV, Gagel RF, Prieto VG, et al. Evaluation and surgical resection of adrenal masses in patients with a history of extra-adrenal malignancy. Surgery. $2001 ; 130: 1060-7$

23. Twomey $\mathrm{P}$, Montgomery $\mathrm{C}$, Clark O. Successful treatment of adrenal metastases from large-cell carcinoma of the lung. JAMA. $1982 ; 248: 581-3$

24. Reyes L, Parvez Z, Nemoto T, Regal AM, Takita H. Adrenalectomy for adrenal metastasis from lung carcinoma. J Surg Oncol. 1990;44:324.

25. Siemer S, Lehmann J, Kamradt J, Loch T, Remberger K, Humke U, et al. Adrenal metastases in 1635 patients with renal cell carcinoma: outcome and indication for adrenalectomy. J Urol. 2004;171:2155-9.

26. Luketich JD, Burt ME. Does resection of adrenal metastases from non-small cell lung cancer improve survival? Ann Thorac Surg. $1996 ; 62: 1614-6$.

27. Higashiyama M, Doi O, Kodama K, Yokouchi H, Imaoka S, Koyama H. Surgical treatment of adrenal metastasis following pulmonary resection for lung cancer: comparison of adrenalectomy with palliative therapy. Int Surg. 1994;79:124-9. 
28. Porte H, Siat J, Guibert B, Lepimpec-Barthes F, Jancovici R, Bernard A, et al. Resection of adrenal metastases from non-small cell lung cancer: a multicenter study. Ann Thorac Surg. 2001;71:981-5.

29. Kim SH, Brennan MF, Russo P, Burt ME, Coit DG. The role of surgery in the treatment of clinically isolated adrenal metastasis. Cancer. 1998;82:389-94.

30. Moinzadeh A, Gill IS. Laparoscopic radical adrenalectomy for malignancy in 31 patients. J Urol. 2005;173: 519-25.

31. Gill IS. The case for laparoscopic adrenalectomy. J Urol. $2001 ; 166: 429-36$.

32. Chen B, Zhou M, Cappelli MC, Wolf JS Jr. Port site, retroperitoneal and intra-abdominal recurrence after laparoscopic adrenalectomy for apparently isolated metastasis. J Urol. 2002;168:2528-9.

33. Lo CY, van Heerden JA, Soreide JA, Grant CS, Thompson GB, Lloyd $\mathrm{RV}$, et al. Adrenalectomy for metastatic disease to the adrenal glands. Br J Surg. 1996;83:528-31.

34. Rassweiler J, Tsivian A, Kumar AV, Lymberakis C, Schulze M, Seeman O, et al. Oncological safety of laparoscopic surgery for urological malignancy: experience with more than 1,000 operations. J Urol. 2003; 169:2072-5.

35. Tsivian A, Sidi AA. Port site metastases in urological laparoscopic surgery. J Urol. 2003;169:1213-8. 
36. Gerber E, Dinlenc C, Wagner JR. Laparoscopic adrenalectomy for isolated adrenal metastasis. J Soc Laparoendosc Surg. 2004;8:3149.

37. Jones DB, Guo LW, Reinhard MK, Soper NJ, Philpott GW, Connett J, et al. Impact of pneumoperitoneum on trocar site implantation of colon cancer in hamster model. Dis Colon Rectum. 1995;38:1182-8.

38. Mathew G, Watson DI, Ellis T, De Young N, Rofe AM, Jamieson GG. The effect of laparoscopy on the movement of tumor cells and metastasis to surgical wounds. Surg Endosc. 1997;11:1163-6.

39. Tsivian A, Shtabsky A, Issakov J, Gutman M, Sidi AA, Szold A. The effect of pneumoperitoneum on dissemination and scar implantation of intra-abdominal tumor cells. J Urol. 2000;164:2096-8.

40. Ikramuddin S, Lucas J, Ellison EC, Schirmer WJ, Melvin WS. Detection of aerosolized cells during carbon dioxide laparoscopy. J Gastrointest Surg. 1998;2:580-3.

41. Uson AC. Tumor recurrence in the renal fossa and/or the abdominal wall after radical nephrectomy for renal cell carcinoma. Prog Clin Biol Res. $1982 ; 100: 549-60$.

42. Winfield HN, Hamilton BD, Bravo EL, Novick AC. Laparoscopic adrenalectomy: the preferred choice? A comparison to open adrenalectomy. J Urol. 1998;160:325-9.

43. Mayo-Smith WW, Dupuy DE. Adrenal neoplasms: CTguided radiofrequency ablation-preliminary results. Radiology. $2004 ; 231: 225-30$. 
44. Haga H, Saito T, Okumoto K, Sugahara K, Takeda T, Saito K, et al. Successful percutaneous radiofrequency ablation of adrenal metastasis from hepatocellular carcinoma. J Gastroenterol. $2005 ; 40: 1075-6$.

45. Sarela AI, Murphy I, Coit DG, Conlon KC. Metastasis to the adrenal gland: the emerging role of laparoscopic surgery. Ann Surg Oncol. 2003;10:1191-6.

46. Golwyn DH Jr, Routh WD, Chen MY, Lorentz WB, Dyer RB. Percutaneous transcatheter renal ablation with absolute ethanol for uncontrolled hypertension or nephritic syndrome: results in 11 patients with end-stage renal disease. J Vasc Interv Radiol. $1997 ; 8: 527-33$

47. Maki DD, Haskal ZJ, Matthies A, Langer J, Niesenbaum HL, Vaughn D, et al. Percutaneous ethanol ablation of an adrenal tumor. AJR Am J Roentgenol. 2000;174: 1031-2. 